\title{
Performance analysis of the protective effects of bicycle helmets during impact and crush tests in pediatric skull models
}

\author{
Laboratory investigation
}

\author{
Tobias A. Mattei, M.D., ${ }^{1}$ Brandon J. Bond, B.A., ${ }^{2}$ Carlos R. Goulart, B.S., ${ }^{3}$ \\ Chris A. Sloffer, M.D., M.B.A., ${ }^{4}$ Martin J. Morris, Ph.D., ${ }^{4}$ and Julian J. Lin, M.D. ${ }^{1}$ \\ ${ }^{1}$ Department of Neurosurgery, University of Illinois College of Medicine, Illinois Neurological Institute; \\ ${ }^{2}$ University of Illinois College of Medicine; ${ }^{4}$ Department of Mechanical Engineering, Bradley University, \\ Peoria, Illinois; and ${ }^{3}$ Evangelical University of Paraná, Curitiba, Brazil
}

\begin{abstract}
Object. Bicycle accidents are a very important cause of clinically important traumatic brain injury (TBI) in children. One factor that has been shown to mitigate the severity of lesions associated with TBI in such scenarios is the proper use of a helmet. The object of this study was to test and evaluate the protection afforded by a children's bicycle helmet to human cadaver skulls with a child's anthropometry in both "impact" and "crushing" situations.

Methods. The authors tested human skulls with and without bicycle helmets in drop tests in a monorail-guided free-fall impact apparatus from heights of 6 to 48 in onto a flat steel anvil. Unhelmeted skulls were dropped at 6 in, with progressive height increases until failure (fracture). The maximum resultant acceleration rates experienced by helmeted and unhelmeted skulls on impact were recorded by an accelerometer attached to the skulls. In addition, compressive forces were applied to both helmeted and unhelmeted skulls in progressive amounts. The tolerance in each circumstance was recorded and compared between the two groups.

Results. Helmets conferred up to an $87 \%$ reduction in so-called mean maximum resultant acceleration over unhelmeted skulls. In compression testing, helmeted skulls were unable to be crushed in the compression fixture up to 470 pound-force (approximately $230 \mathrm{kgf}$ ), whereas both skull and helmet alone failed in testing.

Conclusions. Children's bicycle helmets provide measurable protection in terms of attenuating the acceleration experienced by a skull on the introduction of an impact force. Moreover, such helmets have the durability to mitigate the effects of a more rare but catastrophic direct compressive force. Therefore, the use of bicycle helmets is an important preventive tool to reduce the incidence of severe associated TBI in children as well as to minimize the morbidity of its neurological consequences.

(http://thejns.org/doi/abs/10.3171/2012.8.PEDS12116)
\end{abstract}
KeY Words - crushing traumatic brain injury $\quad$ - pediatric traumatic brain injury $\bullet$ cadaver skull • bicycle helmet • performance analysis • trauma

$\mathrm{A}$ LTHOUGH several scientific advances have been observed in the clinical management of TBI in the pediatric population in recent years, $, 3,19,39$ preventive measures that might provide a significant impact on the epidemiology of severe TBI in this population have been relegated to a position of secondary importance, both in public policies and in the field of medical research.

\footnotetext{
Abbreviations used in this paper: $\mathrm{BB}=$ ball bearing; $\mathrm{CPSC}=$ Consumer Products Safety Commission; $\mathrm{df}=$ degrees of freedom; $\mathrm{lbf}=$ pound-force; $\mathrm{TBI}=$ traumatic brain injury.
}

According to a recent study involving 42,412 patients in which the prevalence of clinically important TBIs in children was evaluated ${ }^{28}$ bicycle-related injuries are classified among those with increased risk of significant TBI after blunt head trauma, together with high-speed motor vehicle accident, impact a from high-speed projectile, and fall from a height or down stairs. Head injuries are the most common cause of serious disability and death in bicycle accidents. ${ }^{40}$ In one epidemiological study, head injuries were responsible for $32 \%$ of bicycle-associated emergency department visits, $67 \%$ of bicycle-associat- 
ed hospital admissions, and $62 \%$ of bicycle-associated deaths. ${ }^{16}$ Another population-based study of hospitalized brain-injured patients found that $7 \%$ of these injuries were bicycle related. ${ }^{20}$

During the 16-year period from 1990 to 2005, an average of 389,300 patients was seen annually in US emergency departments for bicycle-associated injuries, with hospitalization occurring in nearly $4 \%$ of the cases (approximately 14,700 annual admissions). ${ }^{24}$ More than $12 \%$ of these emergency department visits were the result of head injuries, and $34 \%$ of patients requiring subsequent hospitalization had head injuries. ${ }^{24,34}$ Furthermore, 1965 fatalities were ascribed to bicycle-related injuries during this interval; $40 \%$ resulted from head injury and an additional $28 \%$ were the result of multisystem trauma, many also involving head injury. ${ }^{35}$

Bicycling in the US is a very popular form of recreation, fitness exercise, and transportation. Industry sources estimate that there were nearly 45 million persons of approximately 7 years of age who rode bicycles at least 6 times or more in 2008. ${ }^{1}$ Such a high level of child participation in bicycling implies a correlative number of falls and crashes, many of which may lead to serious injury to the rider.

The pediatric population seems to be disproportionally affected by bicycle-associated injury. This bias is probably commensurate with greater bicycle usage at this age. For example, $70 \%$ of all children between the ages of 5 and 14 years ride bicycles. ${ }^{9}$ In the series of cases treated between 1990 and 2005, 79\% of bicycle-related injuries were in patients between the ages of 5 and 14 years. ${ }^{24}$ In another study, $68 \%$ of severe bicycle-associated head injuries occurred in riders younger than 15 years of age, whereas $29 \%$ occurred in those younger than 9 years of age. ${ }^{40}$

One factor that several studies have shown to mitigate the risk and incidence of serious bicycle-related TBI is the proper use of a bicycle helmet. ${ }^{15,40,42-44}$ Bicycle helmets function to attenuate the energy transferred to the skull on impact by distributing this force. The efficacy of this attenuation is often measured with a drop test wherein a helmeted anthropometric head form is released into a guided free fall within a monorail carriage onto a steel anvil of variable shape (flat, hemispheric, curbstone). The resultant acceleration of the head form on impact, at selected drop heights, is then measured and evaluated.

There has been increasing interest in the neurosurgical literature in the study of the effect of helmets on the prevention of sports-related TBI. ${ }^{5,8,21,31}$ Nevertheless, very few of these studies have included bicycle helmets in their benchmark tests. ${ }^{18}$ Moreover, most of the previous children's bicycle helmet tests have been performed using artificial head forms based on adult anthropometry. These models consequently carry with them inherent fit and stability incongruencies. ${ }^{37}$

The aim of the present study was to quantitatively determine the effectiveness of a children's bicycle helmet in protecting cadaver skulls with child anthropometry in both impact and crushing situations.

\section{Methods}

Studies investigating biomechanical tolerance can be roughly classified into 5 basic categories, as follows: 1) analyses of real-world events (for example, orthopedic injuries, bicycle accidents, or TBIs); 2) human volunteer experiments; 3) animal tests; 4) mathematical simulations; and 5) human cadaver studies. ${ }^{46}$

Although analysis of real-world events may provide important data about the mechanisms of injury as well as several other environment-associated factors, they usually provide little quantification of the actual biomechanical parameters (for example, forces) responsible for the injury being studied. Furthermore, in the case of accidental events, a broad range of healthy individuals (such as racing drivers or bicycle riders for example) should be monitored to obtain data related to the occurrence of such somewhat rare accidental events.

In relation to tests in human volunteers, because of ethical concerns these types of experiments are able to provide biomechanical data only on the "subinjury" levels, and therefore do not constitute a helpful tool for the domain of injury research. ${ }^{13}$

On the other hand, animal tests are able to provide both physiological and injury data. Nevertheless, precise scaling criteria to translate such results to the in vivo scenario are scarce. ${ }^{29}$

The fourth option (mathematical simulations) has the unique ability to provide several parametric variables that may be analyzed simultaneously. Nevertheless, the validation of such results must necessarily be based on practical benchmark experiments. ${ }^{45}$

In contrast, human cadaver experiments provide deterministic data because of the anatomical equivalency of the specimens with living individuals. Furthermore, based on the knowledge of the main forces involved in the injury pattern that is being evaluated, researchers may simulate benchmark situations that reproduce the occurrence of such forces..$^{23}$ Therefore, to evaluate the protective effects of helmets, we validated an experimental setup that is able to test 2 important forces involved in bicycle accidents: "impact" and "crushing."

\section{Impact Testing}

An impact test stand was fabricated to assess the efficacy of a bicycle helmet in the attenuation of impact acceleration rates on a human cadaver skull. This test apparatus comprised a precision rail and a carriage mounted on an I-beam with a welded base that permitted independent standing (Fig. 1 left). This setup allowed for the guided free fall of the test specimens.

We used pediatric skulls obtained in donors ranging from 8 to 10 years of age. This age was selected after a combined analysis of the standard deviation of skull weights obtained from donors ranging from 7 to 15 years. As skull weights were displayed in a Gauss curve, the 8to 10 -year interval was the one that provided the widest range of age with a still acceptable variation of the mean values (a variation calculated to achieve a p value of 0.05 in a comparative test simulated to evaluate 100 different random specimens). 


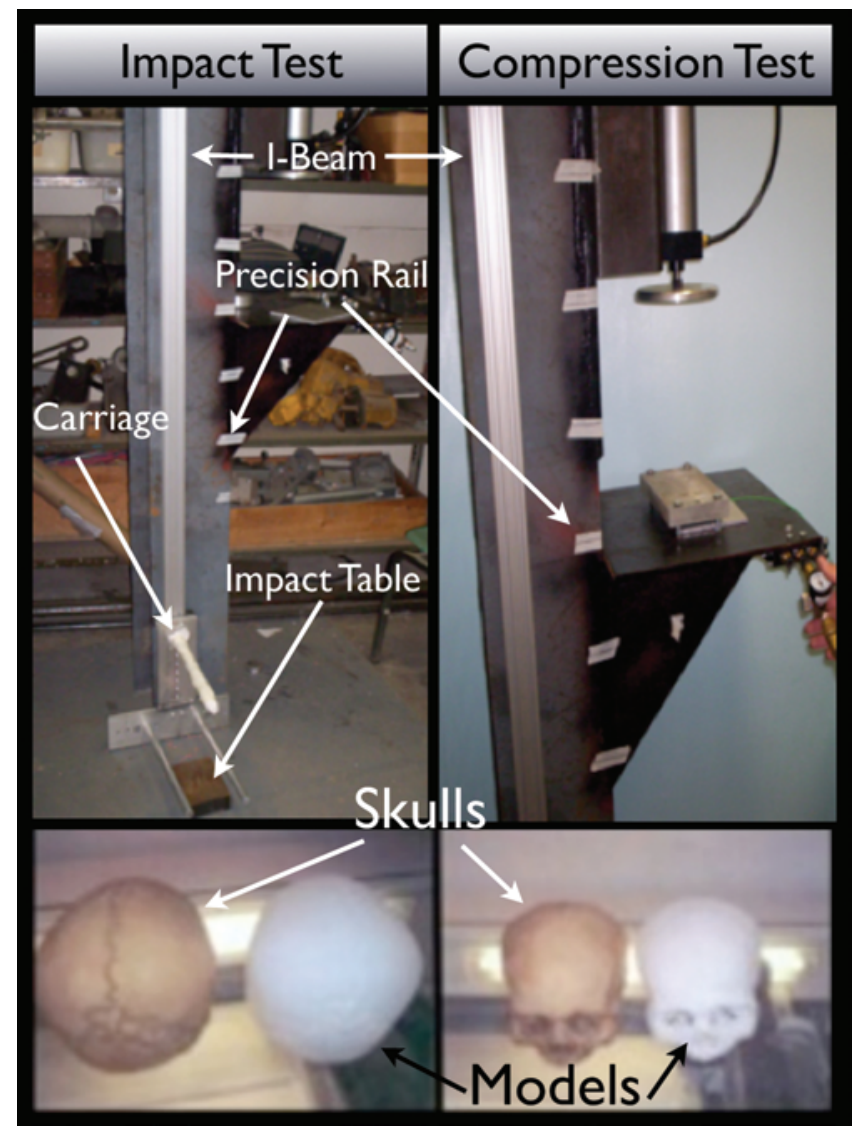

FIG. 1. Photographs of the test stand apparatus constructed for impact (left) and compression testing (right). To test the machines prior to the experiments with the cadaveric skulls, the authors constructed 3D prototypes modeled after the cadaver skulls.

Four cadaver skulls were soaked in room-temperature water for approximately 24 hours to make their mechanical properties more closely represent in situ conditions. The skulls were then filled with BBs so that a uniform weight of $4 \mathrm{lbs}$ could be achieved. The BBs were previously weighed and inserted into the skull through a bur hole (an initial weight of $90 \%$ of the final desired weight was used because to fix the BBs to the skull, we poured in a fast-polymerizing resin cement, which supplied the remaining $10 \%$ weight). This process of fixation of the BBs assured that throughout the whole experiment the only movement detected by the accelerometer would be the one from the whole skull and not from free BBs inside the skull.

In practical terms, first the BBs and the polymerizing cement were inserted through the bur hole in the skull. A round area for the accelerometer in the center of gravity of the skull was protected during the filling with BBs and resin by a plastic ball that did not stick to the resin. This ball was then retrieved, leaving the space free for the insertion of a Kistler accelerometer (Type 8636B500), which was affixed in the protected space. The acceleration data were digitally filtered with a Kistler low-pass 4-channel coupler (Type 5134). Data were accumulated at the prescribed rate of 30,000 samples per second by using a PC-based data acquisition system.
Each skull was fitted with a commercially available representative children's bicycle helmet (Bell Fraction Bike Helmet - Kids) and was individually strapped, upside down, onto the impact carriage attached to the test stand (Fig. 2). The skull and helmet assembly was then released into free fall from selected heights ranging from 6 in to 48 in onto a flat steel impact anvil. Acceleration, in negative $G$ values, was measured to acquire the maximum resultant acceleration (the moment of impact). After impact, the skull was inspected for any visible damage. Damage was defined as any fracture or gross structural alteration that violated the macroscopic integrity of the skull. In cases in which no visible damage was detected, the helmet was changed for a similar one to eliminate the influence of possible fatigue or undetected microdamage to its structure that might influence the subsequent tests. Afterward the helmeted skull was strapped back onto the impact carriage, the drop height was progressively increased, and the procedure was repeated. In cases in which the skull was damaged after a trial, testing for that particular skull was terminated.

This procedure was repeated with an unhelmeted skull from drop heights ranging from 6 in to $48 \mathrm{in.} \mathrm{Again,}$ after each drop the skull was visually inspected for damage. Due to output limitations inherent to the accelerometer, measurement of unhelmeted drop heights above 9 in had to be suspended. Therefore, only test data for unhelmeted skulls subjected to 6-in and 9-in drops were used for comparative purposes, although tests at greater heights were still conducted to examine the resultant damage. The differences in the maximum accelerations experienced by the skull with and without a helmet at analogous drop heights were evaluated.

Data were analyzed using the statistical software SPSS (version 16; SPSS, Inc.). The mean accelerations, standard deviations, and standard error of the means were calculated for each helmet status of the 6-in and 9-in drop tests (Fig. 3). The independent samples t-test was used to examine for group differences. The authors used an inferential statistic (the Levene test) to assess the equality of variances between the populations of the 2 samples. In the 6-in drop test, equal variances were assumed because the F statistic of 7.782 was not significant (0.068). Therefore, we used the $t$ value of 6.448 with $3 \mathrm{df}$, which is a statistically significant difference $(p<0.008)$. The mean differences and $95 \%$ confidence intervals were also interpreted. For the 9-in drop test, equal variances were not assumed (there is no variance in the unhelmeted skull drop data). Therefore, we used the $t$ value of 185 with $1 \mathrm{df}$ ( $p<0.003$ ). Again, the mean differences and 95\% confidence intervals were interpreted.

\section{Compression Testing}

For further assessment of the protective effects conferred by a bicycle helmet, a compression test was developed. This test measured the ability of the helmet to shield a skull from damage in a crush situation. An apparatus that was appended to the side of the I-beam of the impact test stand was constructed for this purpose. This setup used a pneumatic air cylinder connected to an air compressor feeding 170 psi (Fig. 1 right). A platform 


\section{Bicycle helmet protection from traumatic brain injury in children}
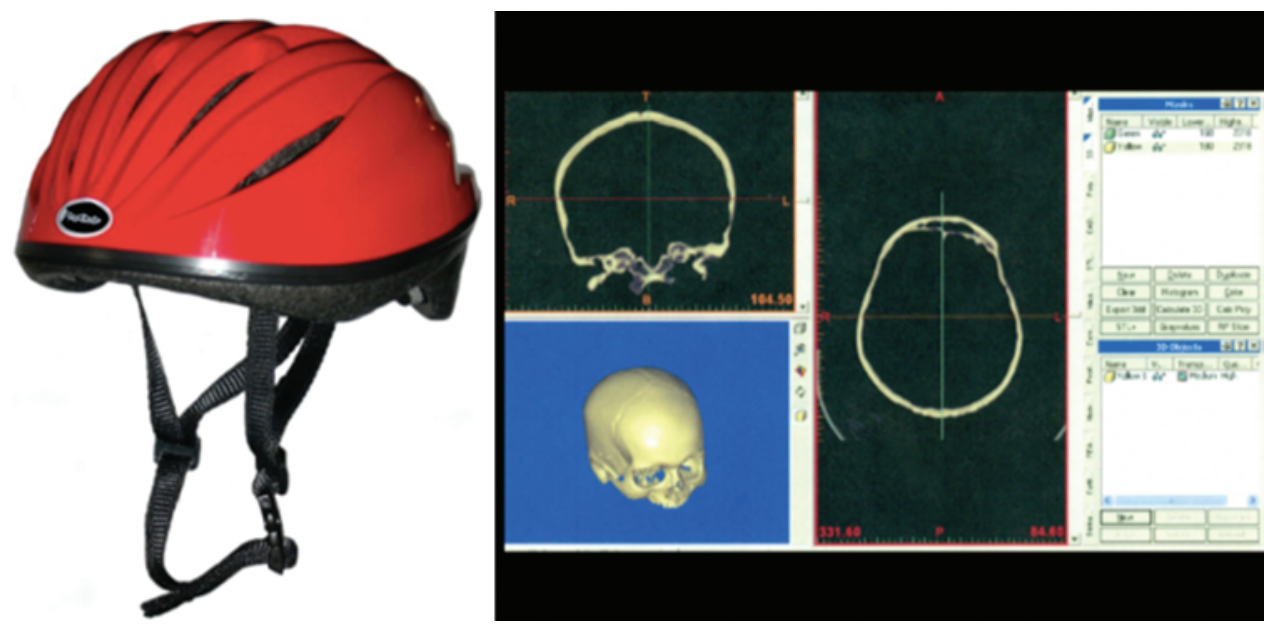

FIG. 2. Photograph of the standard children's bicycle helmet used in the experiment (left). For data analysis the authors used a computer software program (right) that was capable of calculating mean accelerations, standard deviations, and the standard error of the means for each helmet status of the 6-in and 9-in drop tests.

was positioned under the air cylinder that allowed for the placement of the skulls being tested and a Kistler 5000lb load cell (Type 9712A5000). Additionally, a pressure plate was fabricated to fit over the load cell (a transducer that is used to convert a force into electrical signal) to hold it horizontally with the platform. Therefore, this system was able to calculate the force applied to the transducer by providing an electrical output that was plugged into an algorithm to calculate the final applied force.

The test procedure comprised the individual placement of bicycle helmets on their sides on the platform and compressing them with the pneumatic cylinder while recording their load versus time parameters with the data acquisition system. This procedure was repeated for cadaver skulls fitted with a bicycle helmet and cadaver skulls without a helmet. Maximum tolerated loads for each scenario were then evaluated. Both impact and compression testing were conducted on the campus of Bradley University, Peoria, Illinois.

\section{Impact Testing}

\section{Results}

Figure 3 presents the mean results of all impact testing, and Table 1 demonstrates the results of the helmeted and unhelmeted 6-in and 9-in drops. The mean maxi-

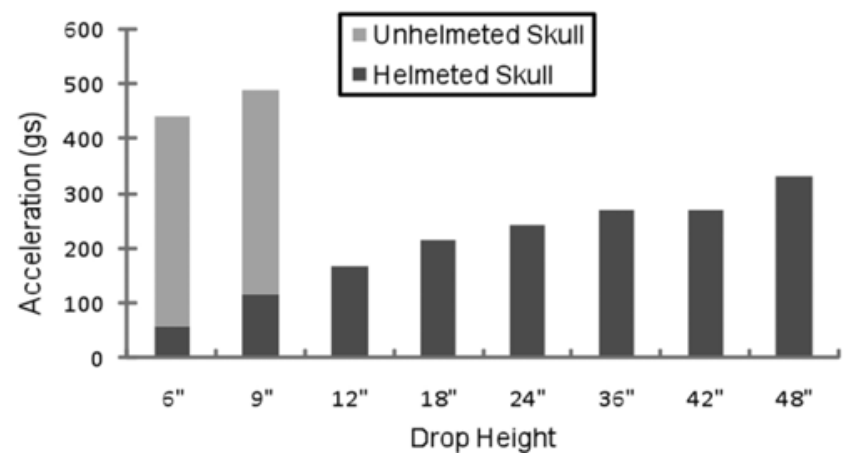

FIG. 3. Bar graph showing the mean maximum resultant acceleration (G) of helmeted and unhelmeted cadaver skulls during impact testing. mum resultant acceleration of the helmeted skull from the 6-in drops was $57 \pm 8 \mathrm{G}$, and the corresponding mean maximum resultant acceleration for the unhelmeted skull at 6 in was found to be $440 \pm 79 \mathrm{G}$ (both values expressed as the mean $\pm \mathrm{SD}$ ). From these data it could be concluded that, at a drop height of 6 in, the unhelmeted skull experienced acceleration 7.7 times greater than the helmeted skull at the same height $(\mathrm{t}=6.448,3 \mathrm{df}, \mathrm{p}<0.008)$.

The mean maximum resultant acceleration of the helmeted skull from the 9-in drops was $117 \pm 3 \mathrm{G}$ (mean $\pm \mathrm{SD}$ ). When unhelmeted, all 9-in drop tests registered acceleration of $487 \mathrm{G}$. Because $487 \mathrm{G}$ was our upper limit value, the actual mean maximum resultant acceleration was at least $487 \mathrm{G}$. Therefore, the unhelmeted skull ex-

TABLE 1: Impact attenuation performance of children's bicycle helmets at 6-in and 9-in drop heights*

\begin{tabular}{lcc}
\hline \multirow{2}{*}{ Variable } & \multicolumn{2}{c}{ Drop Height } \\
\cline { 2 - 3 } & $6-\mathrm{In}$ & $9-\mathrm{In}$ \\
\hline unhelmeted drop test & 3 & 2 \\
no. of drop trials & 440 & 487 \\
mean max acceleration (G) & 79 & 0 \\
SD & 46 & 0 \\
SEM & & \\
helmeted drop test & 2 & 2 \\
no. of drop trials & 57 & 117 \\
mean max acceleration (G) & 8 & 3 \\
SD & 6 & 2 \\
SEM & $87 \%$ & $>76 \%$ \\
acceleration reduction & & \\
statistical analysis & 6.448 & 185 \\
t value & 3 & $<0.003$ \\
df & $<0.008$ & \\
p value &
\end{tabular}

* The maximum measurable output for acceleration was $487 \mathrm{G}$. Abbreviation: $\max =$ maximum. 


\section{T. A. Mattei et al.}

perienced acceleration at least 4.2 times greater than the helmeted skull at the same height $(\mathrm{t}=185,1 \mathrm{df}, \mathrm{p}<0.003)$.

In practical terms this would mean that, regarding the force of the head impact, using the helmet would transform an accident from a child riding a bike at approximately $30 \mathrm{mph}$ (deceleration of $0.45 \mathrm{G}$ ) to approximately $7 \mathrm{mph}$ (deceleration of $0.11 \mathrm{G}$ ) - both scenarios assuming crashes in which the velocities would be reduced to 0 $\mathrm{mph}$ in approximately 3 seconds. Minimization of head acceleration is important inasmuch as it can have direct clinical implications. It has been estimated, for example, that a head acceleration of $200 \mathrm{G}$ correlates to an $80 \%$ likelihood of head injury involving skull facture or intracranial hemorrhage. ${ }^{4}$ Unhelmeted skull impact failure (that is, fracture) was observed in 2 skulls at 24-in and 30in drops. Both failures occurred along the coronal suture.

\section{Compression Testing}

Evaluation of the helmet-only compression data showed initial cracking that occurred in the range of 100 $200 \mathrm{lbf}$. The average cracking force was found to be 140 lbf. The skull and helmet assembly could not be crushed in the compression stand even under the maximum force experienced by the load cell (470 lbf). It could be seen during testing, however, that the helmets without the skull cracked at approximately $190 \mathrm{lbf}$. This is consistent with data from the compression testing provided by the manufacturer of the selected helmet used during the tests. The unhelmeted skull underwent catastrophic failure during testing, experiencing a maximum load of $520 \mathrm{lbf}$.

\section{Discussion}

Previous studies have already demonstrated that one of the most important variables involved in bicycle accidents is the initial impact force on the skull. ${ }^{25,37}$ Although crushing forces are more rare, they also deserve special attention, because bicycle helmets may provide a salvage resource in catastrophic events involving trapped victims under either natural elements (such as trees and stones) or other ones more common in the urban scenario (such as motor vehicles or concrete walls).

Nevertheless, it should be remembered that several other variables may be involved in TBI associated with bicycle accidents. For example, so-called angular acceleration forces may, even in the absence of an impact, result in diffuse axonal injury. ${ }^{12,27}$ Nevertheless such an important variable, which may in fact have a significant influence on the prognosis of pediatric TBI, is not particularly addressed by the use of helmets. In fact, depending on their weight, helmets might even make such an effect worse, because a significant increase in the total head/ helmet weight tends to augment its momentum, increasing the risk not only of deceleration-related brain injuries but also of associated cervical spinal cord injuries. ${ }^{41}$

There are also other types of forces that may be involved in pediatric TBI and for which helmets may offer significant protection, but which have no significant role in pediatric TBI involved in bicycle accidents. Examples of such a group are those forces associated with a sudden dislocation of air (leading to the so-called blast injuries). ${ }^{6}$
In relation to the point of impact, although previous studies have found that the majority of nonfatal bicycle crashes resulted in frontal/temporal region injuries, ${ }^{37,44}$ due to methodological considerations the proposed drop test evaluated the impact force specifically at the top of the helmet. In relation to this fact, some specific considerations are opportune. According to the requirements of the American National Standards Institute for helmet manufacturers, the helmet strength should be uniform in all of its portions. ${ }^{1}$ Therefore, from the standpoint of the helmet, a single hit in any portion of its structure should be representative of hits of similar force in any other point.

The discussion about the impact point relies on the variability of effect of similar forces on the different bones of the skull. Theoretically it can be argued that an impact of the same force in the frontal bone might induce a significant fracture, whereas the same impact on the top of the head might not. Nevertheless, trying to reproduce an impact in the frontal portion of the skull requires a much more complex experimental setup, because in a drop test (the standard scenario used for such evaluations) the head would rotate after the impact. Therefore in such situations the values provided by the accelerometer would not be reliable to evaluate the impact force. Designing such experiments would require a much more sophisticated scenario because a force plate would be necessary to provide a more accurate measurement of impact.

Moreover, recent studies have suggested that the human temporoparietal region of the skull fractures similarly to the frontal and occipital bones because of their constitutional similarity (diploë sandwiched by the inner and outer tables). Therefore, fracture thresholds of the temporoparietal region (expressed in terms of parameters such as impact force) seem to overlap with those of other skull regions, although the mean force needed to fracture may be somewhat lower in some specimens compared with the frontal bone. ${ }^{46}$ Ultimately, because both the helmeted and nonhelmeted skulls were subjected to impact in the same experiment, the comparative analysis between them should eliminate such variables and provide an accurate measure of the difference provided by the use of the helmet, although it would probably not reflect the absolute values.

In relation to the compression test, because most crush situations occur from lateral compression forces, the testing situation very accurately reflects the clinical scenario intended to be reproduced.

Another methodological consideration that must be taken into account when interpreting the results of the present study is the fact that, at any tested height, only one impact was allowed. It is important to understand that such an experimental setup, which evaluated a "one-hit" impact, may differ from real situations in which the head usually undergoes multiple sequential impacts. Nevertheless, because the aim of this study was to evaluate the capacity of the helmets, in terms of the force of the impact, to absorb and attenuate the most substantial impact (the first one), such secondary hits can be considered to have minimal influence on the structure of the helmet/skull assembly and, therefore, on the scientific question that our 


\section{Bicycle helmet protection from traumatic brain injury in children}

experiments proposed to answer. Importantly, only linear acceleration on a flat metal anvil (as opposed to other anvil shapes or surfaces) and not rotational acceleration was measured. Although not evaluated in the present study, rotational acceleration does have clinical implications in that it has been reported to cause neuronal injury due to the shearing forces experienced by neuronal tissue. ${ }^{17}$

In relation to the results of the impact tests, we were able to demonstrate that a children's bicycle helmet can provide measurable protection in terms of reducing by up to $87 \%$ of the linear acceleration experienced by a skull on the introduction of an impact force. Implicit in this performance is the diminution of this impact force's transmission to the brain. Additionally, the compression tests offered dramatic evidence attesting to the helmet's durability via its mitigating effects on an otherwise catastrophic direct compressive force.

Despite the conclusively proven protection offered by bicycle helmets, usage rates remain abysmally low. National estimates report that bicycle helmet use among child bicyclists ranges from $15 \%$ to $25 \% .{ }^{9}$ Bicycle helmet usage has many important public health implications. From a morbidity perspective, riders who do not wear bicycle helmets are at a 6.6-fold greater risk of head injury and an 8.3-fold greater risk of brain injury than bicyclists who do wear helmets (an $85 \%$ and $88 \%$ risk reduction, respectively). ${ }^{40}$

From a financial perspective, the US CPSC has estimated that approximately $\$ 6$ billion is spent annually on medically attended bicycle-related injuries. ${ }^{17,33}$ The imputed cost per life lost in fatalities adds an additional \$2 billion, for a total cost to society of $\$ 8$ billion for bicycleassociated injuries and deaths. Just as bicycle helmet usage has been shown to mitigate head and brain injuries, it should be expected that increased bicycle helmet usage would reduce significantly the impressive costs that bicycle-associated injuries add to the national health care budget.

In a study that assessed the impact of the legislation on the frequency of helmet use in children involved in bicycle crashes who presented to a regional pediatric trauma center in Buffalo, New York, it was found that the recently implemented bicycle helmet safety law resulted in a 13-fold increase in the use of bicycle helmets among the children admitted to this hospital after bicycle crashes. ${ }^{36}$

In fact, it has already been shown that adherence to legislation may lead to a significant change in bicyclerelated TBI. According to the Howard County health office, after the implementation of strict legislation the rate of bicycle helmet use by children in that location is now the highest documented for children in the US. It was estimated that a similar increase in helmet use among children younger than 16 years of age nationwide could prevent approximately 100 deaths and 56,000 head injuries treated in emergency departments annually. ${ }^{11}$

In a recent Cochrane review it was reported that bicycle helmet legislation appears to be effective in increasing helmet use and decreasing head injury rates in the populations for which it was implemented. However, this review concluded that there are still very few high-quality studies measuring such outcomes. ${ }^{22}$
Although all bicycle helmets sold in the US must comply with mandatory federal safety standards set forth by the US CPSC, manufacturers can seek certification according to other more stringent standards. ${ }^{1,2,10,38}$ Despite the plethora of worldwide standards that exist, those helmets that perform with a very low G-force measurement in drop tests similar to those conducted in this study are deemed most effective at impact force attenuation.

It should be noted that in our testing we used only one children's bicycle helmet model, and therefore the performance of this helmet may not be broadly extrapolative to other models. Inasmuch as there are a variety of comparable helmet models with varying characteristics (that is, liner foam thickness and density, outer shell stiffness, retention system design), it is reasonable to assume that a continuum of performance exists among models on the market. ${ }^{7}$ Although in this initial pilot study no attempt was made to undertake comparative testing between a broader range of helmets, the next step in this line of research is to test several of the helmet models available in the market and compare their properties in relation to the values obtained in this initial pilot study.

In an effort to participate in the promotion of bicycle helmet usage, our testing was recorded on video, and the footage has been incorporated into a public service announcement video advocating the use of bicycle helmets. The dramatic protective effect afforded to the skull by the helmet is demonstrated in this promotional film (Video 1).

VIDEO 1. Clip showing a public service video created for a local community campaign aiming to increase the adherence to bicycle helmet usage laws among the pediatric population. The video depicts the remarkable difference between helmeted and unhelmeted skulls in the compression test. Click here to view with Media Player. Click here to view with Quicktime.

There is a plan for the near future to televise this video as well as to use it in an Internet-based context as part of an effort to support a local campaign of bicycle helmet usage, with particular emphasis on the pediatric population. As other studies have already demonstrated, such community-wide campaigns can significantly increase the use of bicycle helmets among children and provide a meaningful impact in the prevention of bicycle-associated head injuries..$^{14,26,30,32}$

\section{Conclusions}

Children's bicycle helmets provide measurable protection in terms of attenuating the acceleration experienced by a skull upon the introduction of an impact force. Moreover such helmets possess the durability to mitigate the effects of a more rare, but catastrophic direct compressive force. Therefore, the use of bicycle helmets constitutes an important preventive tool to reduce the incidence of TBI in children and to minimize its associated morbidity.

\section{Disclosure}

There is no conflict of interest because funding was not received from any helmet manufacturer, and no author has a business or professional affiliation with any entity related to the bicycle industry. 
Author contributions to the study and manuscript preparation include the following. Conception and design: Bond, Sloffer, Morris. Acquisition of data: Bond. Analysis and interpretation of data: Morris. Drafting the article: Mattei, Goulart. Critically revising the article: all authors. Reviewed submitted version of manuscript: all authors. Approved the final version of the manuscript on behalf of all authors: Mattei. Study supervision: Lin.

\section{Acknowledgments}

The authors gratefully acknowledge Mary Ellen Simpson, Ph.D., R.N., University of Illinois College of Medicine at Peoria, for her assistance in the statistical analysis of the testing data; JoAnna Fleckenstein, Illinois Neurological Institute, Peoria, Illinois, for her assistance in the preparation of the manuscript; and Kamila M. Bond, Illinois Mathematics and Science Academy, for the production of the public service announcement video. Also, the authors express appreciation to Bradley University for the use of their facilities for testing.

\section{References}

1. American National Standards Institute: American National Standard for Protective Headgear: For Bicyclists. New York: American National Standards Institute, 1984

2. American Society of Testing and Materials Committee on Standards: Standard Specification for Protective Headgear Used in Bicycling. Philadelphia: American Society for Testing and Materials, 1993

3. Appelboom G, Zoller SD, Piazza MA, Szpalski C, Bruce SS, McDowell MM, et al: Traumatic brain injury in pediatric patients: evidence for the effectiveness of decompressive surgery. Neurosurg Focus 31(5):E5, 2011

4. Asiminei AG, Vanden Bosche K, Van der Perre G, Verpoest I, Goffin J: A comparison study of different cyclist helmet designs by finite element analysis. Proceedings of the $\mathbf{2 0 0 8}$ Finite Element Workshop 1:13-23, 2008

5. Bartsch A, Benzel E, Miele V, Prakash V: Impact test comparisons of 20th and 21st century American football helmets. Laboratory investigation. J Neurosurg 116:222-233, 2012

6. Bass CR, Panzer MB, Rafaels KA, Wood G, Shridharani J, Capehart B: Brain injuries from blast. Ann Biomed Eng 40:185-202, 2012

7. Benz G, McIntosh A, Kallieris D, Daum R: A biomechanical study of bicycle helmets' effectiveness in childhood. Eur J Pediatr Surg 3:259-263, 1993

8. Chaze B, McDonald P: Head injuries in winter sports: downhill skiing, snowboarding, sledding, snowmobiling, ice skating and ice hockey. Neurol Clin 26:325-332, xii-xiii, 2008

9. Cody BE, Quraishi AY, Mickalide AD: Headed for Injury: An Observational Survey of Helmet Use Among Children Ages 5 to 14 Participating in Wheeled Sports. Washington, DC: National SAFE KIDS Campaign, 2004 (http://www. vahealth.org/injury/TBI/documents/2010/pdfs/researchreport-bike-2004.pdf) [Accessed August 23, 2012]

10. Consumer Product Safety Commission: Part II: 16 CFR Part 1203 Safety Standard for Bicycle Helmets; Final Rule. Fed Regist 63:11711-11747, 1998 (http://www.cpsc.gov/businfo/ frnotices/fr98/10mr98r.pdf) [Accessed August 24, 2012]

11. Coté TR, Sacks JJ, Lambert-Huber DA, Dannenberg AL, Kresnow MJ, Lipsitz CM, et al: Bicycle helmet use among Maryland children: effect of legislation and education. Pediatrics 89:1216-1220, 1992

12. Davidsson J, Risling M: A new model to produce sagittal plane rotational induced diffuse axonal injuries. Front Neurol 2:41, 2011

13. DeRosia J, Yoganandan N: Lessons from staged rear-end collisions using human volunteers, in Yoganandan N, Pintar F (eds): Frontiers in Whiplash Trauma: Clinical and Biomechanical. Amsterdam: IOS Press 2000 pp 265-294
14. DiGuiseppi CG, Rivara FP, Koepsell TD, Polissar L: Bicycle helmet use by children. Evaluation of a community-wide helmet campaign. JAMA 262:2256-2261, 1989

15. Dorsch MM, Woodward AJ, Somers RL: Do bicycle safety helmets reduce severity of head injury in real crashes? Accid Anal Prev 19:183-190, 1987

16. Friede AM, Azzara CV, Gallagher SS, Guyer B: The epidemiology of injuries to bicycle riders. Pediatr Clin North Am 32:141-151, 1985

17. Higgins M, Halstead PD, Snyder-Mackler L, Barlow D: Measurement of impact acceleration: mouthpiece accelerometer versus helmet accelerometer. J Athl Train 42:5-10, 2007

18. Hoshizaki B, Vassilyadi M, Post A, Oeur A: Performance analysis of winter activity protection headgear for young children. Laboratory investigation. J Neurosurg Pediatr 9:133138, 2012

19. Kan P, Amini A, Hansen K, White GL Jr, Brockmeyer DL, Walker ML, et al: Outcomes after decompressive craniectomy for severe traumatic brain injury in children. J Neurosurg 105 (5 Suppl):337-342, 2006

20. Kraus JF, Fife D, Conroy C: Incidence, severity, and outcomes of brain injuries involving bicycles. Am J Public Health 77:76-78, 1987

21. Levy S, Fulton K, Shaver K, Bonville M: Helmets for skiers and snowboarders: head injury prevention through intervention, a pilot program. Neurosurgery 45:696, 1999 (Abstract)

22. Macpherson A, Spinks A: Bicycle helmet legislation for the uptake of helmet use and prevention of head injuries. Cochrane Database Syst Rev 16:CD005401, 2008

23. Meaney DF, Miller RT, Shreiber DI, Smith DH: Experimental modals of traumatic brain injury, in Yoganandan N, Pintar FA, Larson SJ, et al (eds): Frontiers in Head and Neck Trauma: Clinical and Biomechanical. Amsterdam: IOS Press, 1998, pp 169-182

24. Mehan TJ, Gardner R, Smith GA, McKenzie LB: Bicyclerelated injuries among children and adolescents in the United States. Clin Pediatr (Phila) 48:166-173, 2009

25. Mills NJ: Protective capability of bicycle helmets. Br J Sports Med 24:55-60, 1990

26. Morris BAP, Trimble NE: Promotion of bicycle helmet use among schoolchildren: a randomized clinical trial. Can J Public Health 82:92-94, 1991

27. Niess C, Grauel U, Toennes SW, Bratzke H: Incidence of axonal injury in human brain tissue. Acta Neuropathol 104:7984,2002

28. Nigrovic LE, Lee LK, Hoyle J, Stanley RM, Gorelick MH, Miskin M, et al: Prevalence of clinically important traumatic brain injuries in children with minor blunt head trauma and isolated severe injury mechanisms. Arch Pediatr Adolesc Med 166:356-361, 2012

29. Ommaya A, Yarnell P, Hirsch A, Harris E: Scaling of experimental data on cerebral concussion in sub-human primates to concussion threshold in man, in: 10th STAPP Car Crash Conference Proceedings. Los Angeles: Society of Automotive Engineers, 1967, pp 73-80

30. Parkin PC, Spence LJ, Hu X, Kranz KE, Shortt LG, Wesson DE: Evaluation of a promotional strategy to increase bicycle helmet use by children. Pediatrics 91:772-777, 1993

31. Pellman EJ, Viano DC, Withnall C, Shewchenko N, Bir CA, Halstead PD: Concussion in professional football: helmet testing to assess impact performance-part 11. Neurosurgery 58:78-96, 2006

32. Rivara FP, Thompson DC, Thompson RS, Rogers LW, Alexander B, Felix D, et al: The Seattle children's bicycle helmet campaign: changes in helmet use and head injury admissions. Pediatrics 93:567-569, 1994

33. Rodgers GB: Bicycle and bicycle helmet use patterns in the United States. A description and analysis of national survey data. Accid Anal Prev 27:43-56, 1995 


\section{Bicycle helmet protection from traumatic brain injury in children}

34. Sacks JJ, Holmgreen P, Smith SM, Sosin DM: Bicycle-associated head injuries and deaths in the United States from 1984 through 1988. How many are preventable? JAMA 266:30163018, 1991

35. Selbst SM, Alexander D, Ruddy R: Bicycle-related injuries. Am J Dis Child 141:140-144, 1987

36. Shafi S, Gilbert JC, Loghmanee F, Allen JE, Caty MG, Glick $\mathrm{PL}$, et al: Impact of bicycle helmet safety legislation on children admitted to a regional pediatric trauma center. J Pediatr Surg 33:317-321, 1998

37. Smith TA, Tees D, Thom DR, Hurt HH Jr: Evaluation and replication of impact damage to bicycle helmets. Accid Anal Prev 26:795-802, 1994

38. Snell Memorial Foundation: 1990 Standard for Protective Headgear for Use in Bicycling, 1998 Revision. North Highlands, CA: Snell Memorial Foundation, 1990 (http://www. smf.org/standards/pdf/b95rev.pdf) [Accessed August 24, 2012]

39. Taylor A, Butt W, Rosenfeld J, Shann F, Ditchfield M, Lewis E, et al: A randomized trial of very early decompressive craniectomy in children with traumatic brain injury and sustained intracranial hypertension. Childs Nerv Syst 17:154-162, 2001

40. Thompson RS, Rivara FP, Thompson DC: A case-control study of the effectiveness of bicycle safety helmets. N Engl J Med 320:1361-1367, 1989

41. Torg JS, Vegso JJ, O’Neill MJ, Sennett B: The epidemiologic, pathologic, biomechanical, and cinematographic analysis of football-induced cervical spine trauma. Am J Sports Med 18:50-57, 1990

42. Wasserman RC, Buccini RV: Helmet protection from head injuries among recreational bicyclists. Am J Sports Med 18:96-97, 1990
43. Wasserman RC, Waller JA, Monty MJ, Emery AB, Robinson DR: Bicyclists, helmets and head injuries: a rider-based study of helmet use and effectiveness. Am J Public Health 78:1220-1221, 1988

44. Williams M: The protective performance of bicyclists' helmets in accidents. Accid Anal Prev 23:119-131, 1991

45. Yoganandan N, Myklebust JB, Ray G, Sances A Jr: Mathematical and finite element analysis of spine injuries. Crit Rev Biomed Eng 15:29-93, 1987

46. Yoganandan N, Pintar FA: Biomechanics of temporo-parietal skull fracture. Clin Biomech (Bristol, Avon) 19:225-239, 2004

Manuscript submitted March 2, 2012.

Accepted August 21, 2012.

Please include this information when citing this paper: published online October 2, 2012; DOI: 10.3171/2012.8.PEDS12116. Supplemental online information:

Video: http://mfile.akamai.com/21490/wmv/digitalwbc.download. akamai.com/21492/wm.digitalsource-na-regional/peds12-116_ video_NEW.asx (Media Player).

http://mfile.akamai.com/21488/mov/digitalwbc.download.akamai. com/21492/qt.digitalsource-global/peds12-116_video_NEW.mov (Quicktime).

Address correspondence to: Tobias A. Mattei, M.D., Department of Neurosurgery, Illinois Neurological Institute, 530 NE Glen Oak, No.7430, Peoria, Illinois 61637. email: tobiasmattei@yahoo.com. 